\title{
The preventive effect of prostaglandins on postpartum haemorrhage after normal deliveries and caesarean sections
}

\author{
Stavros Kourakos ${ }^{1}$, Georgia Kourakos ${ }^{1}$, Stefanos Zervoudis ${ }^{1-3 *}$, Panagiotis Tsikouras ${ }^{3}$, Panagiotis Peitsidis ${ }^{1}$, Anastasia Bothou ${ }^{2}$, Anisa \\ Markja $^{2}$ and Georgios Iatrakis ${ }^{1}$
}

${ }^{1}$ REA Hospital, Athens, Greece

${ }^{2}$ Department of Midwifery, University of West Attica, Athens, Greece

${ }^{3}$ Department of Obstetrics and Gynecology, Democritus University of Thrace

\begin{abstract}
Purpose: To «count» the prophylactic effect of prostaglandins administration (misoprostol with or without the co-administration of prostaglandin F2a) in the postpartum haemorrhage after normal delivery and after cesarean section.

Material-Methods: The study took place in Athens, Greece during the period 1990-2018. The cases included in the study were divided into 2 groups. No prophylactic uterotonic agent was administered in the patients of the first group which included 335 normal deliveries and 205 cesarean sections. On the contrary, prophylactic administration of misoprostol and, if necessary, the additional administration of prostaglandin F2a was performed in all patients of the second group which included 498 normal deliveries and 377 cesarean sections.
\end{abstract}

Results: The prophylactic administration of prostaglandins resulted in the prevention of postpartum haemorrhage with no need for blood transfusion or invasive procedures.

Conclusion: The prophylactic administration of prostaglandins results in the prevention of postpartum haemorrhage after both normal deliveries and cesarean sections.

\section{Introduction}

Postpartum haemorrhage (PPH) is defined as the loss of more than $500 \mathrm{ml}$ of blood after vaginal delivery and more than $1000 \mathrm{ml}$ after caesarean section (CS). Most occur within 24 hours following labour and are called early PPH. Late PPH is defined as excessive bleeding occurring between 24 hours after delivery and 6 weeks postpartum. Blood loss occurs in $4 \%$ of vaginal deliveries and $6 \%$ of caesarean deliveries. Two percent of cases are presented with severe bleeding [1]. A decline in haematocrit of 10 points has been proposed as a definition of PPH [2].

Blood flow to the gravid uterus at term is 800 to $1000 \mathrm{ml} / \mathrm{min}$ and large amounts of blood can be lost rapidly [3]. Without mechanisms to minimize blood loss, maternal exsanguination could occur rapidly. The uterus contracts after delivery of the placenta and this contraction (rather than formation of clots or aggregation of platelets) is the major mechanism for haemostasis after delivery. Strategies to treat early PPH first must ensure uterine contraction and then identify and repair possible genital tract injuries, retained placenta/membranes and coagulation failure. Fifty percent of early $\mathrm{PPH}$ cases are due to uterine atony [4]. If the uterus is contracted, the leading causes of early PPH include genital tract trauma and pathologic placentation.

500.000 maternal deaths occur worldwide every year. Up to $50 \%$ of these can be attributed to obstetric haemorrhage. As a result, obstetric haemorrhage is associated with significant mortality [5] and is the third leading cause of direct maternal death [6]. Risk factors and causes of $\mathrm{PPH}$ are included in Tables 1 and 2 respectively.
Table 1. Risk factors for postpartum haemorrhage [7]

Prior postpartum haemorrhage

Advanced maternal age

Multifetal gestation

Prolonged labour

Polyhydramnios

Instrumental delivery

Fetal demise

Placental abruption

Anticoagulation therapy

Multiparity

Fibroids

Prolonged use of oxytocine

Macrosomia

Caesarean delivery

Placenta praevia and placenta accreta

Chorioamnionitis

General anaesthesia

*Correspondence to: Stefanos Zervoudis, REA Maternity Hospital, Andrea Syggrou Avenue 383, Paleo Faliro, 17564, Attica, Greece, E-mail: szervoud@otenet.gr

Key words: postpartum hemorrhage, misoprostol, prostaglandin F2a, normal delivery, caesarean section

Received: July 28, 2020; Accepted: September 24, 2020; Published: September 30,2020 
Table 2. Causes of postpartum haemorrhage [7]

\begin{tabular}{|l|}
\hline Early causes \\
\hline Uterine atony ( $50 \%$ of cases) \\
\hline Genital tract lacerations ( $20 \%$ of cases) \\
\hline Retained products $(5-10 \%$ of cases) \\
\hline Abnormal placentation \\
\hline Coagulopathies and anticoagulation \\
\hline Uterine inversion \\
\hline Amniotic fluid embolism \\
\hline Late causes \\
\hline Retained products \\
\hline Uterine infection \\
\hline Subinvolution \\
\hline Anticoagulation \\
\hline
\end{tabular}

The most important aspect of PPH management and treatment is prediction and prevention. A detailed medical history is necessary to determine the risk factors for PPH (Table 1). Immediately following placenta delivery, uterotonic agents should be administered in order to prevent uterine atony (Table 3). The active management of the third stage of labour has been shown to reduce the risk of PPH by $40 \%$ [4].

If bleeding persists, the patient should be transferred for surgical management.

Surgical management [8]

- Examination under anesthesia

- Direct uterine message

- Uterine packing/tamponade

- Compression sutures

- Pelvic devascularization (ligation of the uterine arteries-tubal branches of both ovarian arteries-internal iliac arteries)

- Hysterectomy

This study aims to the treatment and reduction of $\mathrm{PPH}$.

\section{Material and methods}

The goal of this study is to demonstrate a new possible prophylactic therapy against $\mathrm{PPH}$, by administering Misoprostol and, if necessary, prostaglandin F2a after vaginal delivery or CS.

This study took place in Athens, Greece (Mitera and Rea hospitals) during the period 1990-2018. The cases included in the study were divided into 2 groups.

- In the first group (1990-2002), 540 childbirths were included (335 normal deliveries and $205 \mathrm{CS}$ ). No prophylactic administration of Misoprostol or prostaglandin F2a has been performed in this group.

- In the second group (2003-2018), 875 childbirths were included (498 normal deliveries and 377 CS). Prophylactic administration of Misoprostol and, if necessary, the additional administration of prostaglandin F2a has been performed in this group.

\section{Statistical results and further detailed investigation}

1st study group including 540 childbirths (1990-2002) without the prophylactic administration of misoprostol or prostaglandin F2a.

The women's features of this group are included in Table 4.

Out of 540 childbirths, CS account for 205 (38\%) and normal deliveries for 335 (62\%).
As uterine stimulants, $10 \mathrm{IU}$ of oxytocin and $0.5 \mathrm{mg}$ of ergometrine were administered.

a) Significant blood loss (PPH) and haematocrit (HCT) decrease of more than 10\% occurred in $\mathbf{1 6}$ normal deliveries out of the total 355 (Table 5).

PPH cases after normal delivery were managed with the administration of additional $40 \mathrm{IU}$ in $500 \mathrm{ml} \mathrm{n} /$ saline at a rate of 125 $\mathrm{ml} /$ hour (10 IU/hour). Each of 6 women received 4 units of blood. 10 women were treated conservatively (uterine tamponade)

b) Significant blood loss (PPH) and haematocrit (HCT) decrease of more than $10 \%$ occurred in $\mathbf{1 4}$ CS cases out of the total 205 (Table 5). Two cases suffered from placenta praevia.

PPH cases after CS were managed with the administration of additional $40 \mathrm{IU}$ in $500 \mathrm{ml} \mathrm{n} / \mathrm{saline}$ at a rate of $125 \mathrm{ml} /$ hour (10 IU/hour). One woman underwent obstetric hysterectomy without ovaries. Each of four and six women received six units and four units of blood respectively. Three women were treated conservatively.

2nd study group including 875 childbirths (2003-2018) with the prophylactic administration of Misoprostol and, if necessary, the additional administration of prostaglandin F2a.

This group included 875 women who gave birth with CS or vaginal delivery (Table 6) and were treated with the prophylactic administration of prostaglandins. Women with cardiological and/or respiratory disorders and cases with a history of hypertension and allergies were excluded from the study.

Out of 875 childbirths, CS accounted for 377 (43\%) of the deliveries while 498 (57\%) were vaginal births.

Table 3. Pharmacological management of postpartum haemorrhage [8]

\begin{tabular}{|c|c|}
\hline DRUG & DOSE \\
\hline Oxytocin & 5-10 IU IM bolus (if not given at delivery) \\
\hline $\begin{array}{l}\text { Oxytocin } \\
\text { infusion }\end{array}$ & $40 \mathrm{IU}$ in $500 \mathrm{ml}$ normal saline at a rate of $125 \mathrm{ml} /$ hour ( $10 \mathrm{IU} /$ hour $)$ \\
\hline Ergometrine & $\begin{array}{c}0.5 \mathrm{mg} \text { IM or IV* (Avoid in: Hypertension, Preeclampsia, } \\
\text { Cardiovascular Disease) }\end{array}$ \\
\hline $\begin{array}{l}\text { Prostaglandin F2 } \\
\text { alpha }\end{array}$ & $\begin{array}{c}250 \mathrm{mcg} \text { IM can be given every } 15 \text { minutes up to a maximum of } 8 \\
\text { doses ( } 2 \text { micrograms) or a single dose } 2 \mathrm{mg} \text { (effective in most patients) }\end{array}$ \\
\hline Misoprostol & $800-1000$ micrograms can be administered rectally: 4 or 5 tablets \\
\hline
\end{tabular}

Table 4. Women's features of the group treated without the prophylactic administration of misoprostol +- PGF2 $\alpha$

Maternal age: 29 years old (average)

Bleeding history during pregnancy: 48 labours (9\%)

Obstetric history (labours)

Primigravida

Gravida 2

Gravida 3

Total

\begin{tabular}{|c|c|}
\hline & \\
\hline $\mathbf{n}$ & \% \\
\hline 265 & 49 \\
\hline 243 & 45 \\
\hline 32 & 6 \\
\hline 540 & 100 \\
\hline
\end{tabular}

Table 5. Cases with postpartum haemorrhage after normal delivery and after caesarean section

\begin{tabular}{|c|c|c|}
\hline & Normal delivery & Caesarian section \\
\hline Primigravida: & 5 & 3 \\
\hline Gravida 2: & 3 & 5 \\
\hline Gravida 3: & 8 & 6 \\
\hline Total & $\mathbf{1 6}$ & $\mathbf{1 4}$ \\
\hline $\begin{array}{c}\text { Bleeding history during } \\
\text { pregnancy: }\end{array}$ & 3 & 2 \\
\hline
\end{tabular}


a) Significant blood loss (PPH) occurred in 21 normal deliveries.

In this group: 1) No more than $10 \%$ decrease of haematocrit was observed postoperatively, except in two cases. 2) Just one case received 2 blood units and minor lochia rubra were observed for 24-72 hours. 3) No invasive procedure was performed (including obstetric hysterectomy), neither uterine tamponade nor transfer in the operation room. Out of the aforementioned 21 normal deliveries, from the onset of blood loss (PPH), a single dose of $2 \mathrm{mg}$ F2a prostaglandin was administered intracervically for uterine atony. The appropriate genitourinary examination was already performed. As uterotonic agents, a single dose of $10 \mathrm{IU}$ oxytocin and $0.5 \mathrm{mg}$ ergometrine were given (this differs from the CS cases described previously where $600 \mathrm{mg}$ misoprostol was administered rectally after the fetal delivery).

b) Significant blood loss (PPH) occurred in 27 CS cases, including 4 cases with placenta praevia. In one of placenta praevia cases, the woman's medical history included cryoglobulinemia and $8.2 \mathrm{~g} \mathrm{Hb}$ preoperatively. After the CS, this patient did not need to receive any blood. Another case with placenta praevia (percreta), after CS, an Asherman syndrome became obvious after the delivery of the fetus. The patient had a medical history of recurrent abortions during the second trimester. Furthermore, a uterine body with partial myometrial deficit was observed (half of the uterine cavity had a strong adhesion partially attached to the endometrium and partially attached to the uterine serosa). The greater part of the invasive placenta ( $2 / 3$ of its surface) was impossible to be detached. The transfusion requirements for that patient were 2 blood units. The woman was discharged from the hospital the 4 th postoperative day and she took antibiotics and uterotonic agents for 30 days. For 45 days, she was expelling retained placental products. Sixty days later, her uterus had returned to a normal size and, according to an ultrasound examination, the strong adhesions of the uterine cavity (observed during the surgery) were resolved.

In one case, after twin delivery with CS, the operation was accompanied by massive obstetric haemorrhage (with an initial haemoglobin of $13.5 \mathrm{~g} \mathrm{Hb}$ ). In more detail, after the delivery of fetuses - placentas, and the uterus positioned out of the abdominal cavity, a massive bleeding surface was observed at the uteral implantation site of the placenta on the posterior wall of the uterus. Thirty seconds after immediate infusion of F2a (given on different parts of the bleeding surface), the torrential bleeding picture "dried out", even though the incision of the uterus was still open, and the uterus was not contracted. The patient came out of the operating room with 8.5 $\mathrm{g} \mathrm{Hb}$. Due to this case, F2a has been recommended to be available for immediate use in surgery.

For the PPH cases which were performed with CS, $600 \mathrm{mg}$ misoprostol was administered rectally, simultaneously with the uterine transverse incision. The 4 placenta praevia cases, of which 1 was percreta, were treated with $1000 \mathrm{mg}$ misoprostol rectally, simultaneously with the uterine transverse incision. The average time of delivery of the fetus was 5 minutes after the CS induction. From the onset of blood loss (PPH), a single dose of $2 \mathrm{mg}$ F2a was administered on the bleeding surface of the uterus, followed by immediate closure of the incision [9].

The combination of misoprostol [10-12] that causes severe maternal contractions and prostaglandin F2a [9] that causes severe vasospasm, provided us with excellent control of excessive blood loss $(\mathrm{PPH})$ in normal births and CS (Table 7).
Table 6. Women's features of the group treated with the prophylactic misoprostol and +PGF $2 \alpha$

\begin{tabular}{|l|c|c|}
\hline Maternal age: 31 years old (average) & & \\
\hline Bleeding history during pregnancy: 87 labours (10\%) & & \\
\hline Obstetric history (labours) & $\mathbf{n}$ & $\mathbf{\%}$ \\
\hline Primigravita & 507 & 58 \\
\hline Gravida 2 & 342 & 39 \\
\hline Gravida 3 & 26 & 3 \\
\hline Total & 857 & 100 \\
\hline
\end{tabular}

Table 7. Cases with postpartum haemorrhage after normal delivery and after caesarean section

\begin{tabular}{|c|c|c|}
\hline & Normal delivery & Caesarean section \\
\hline Primigravida & 8 & 6 \\
\hline Gravida 2 & 4 & 8 \\
\hline Gravida 3 & 9 & 13 \\
\hline Total & $\mathbf{2 1}$ & $\mathbf{2 7}$ \\
\hline $\begin{array}{c}\text { Bleeding history during } \\
\text { pregnancy }\end{array}$ & 3 & 4 \\
\hline
\end{tabular}

\section{Discussion}

Most PPHs occur within 24 hours following labour and that possibility is greater after caesarean deliveries. Without appropriate measures (medical and/or surgical) to minimize blood loss, maternal exsanguination could occur rapidly. Considering that one in two of early $\mathrm{PPH}$ cases are due to uterine atony, strategies to treat early $\mathrm{PPH}$ first must ensure uterine contraction. The identification and repair of possible genital tract injuries, the management of retained placenta/ membranes and the diagnosis and treatment of coagulation failure are included in possible next steps of PPH treatment. Considering that obstetric haemorrhage is associated with significant mortality, rapid diagnosis and treatment are necessary in every case of PPH.

A drawback of our study is that we did not study the effectiveness of misoprostol according to different stratifications of our data. As an example, apart from "classic" risk factors related to PPH, other purported risk factors, such as body mass index [13] could be further investigated if available in patients' medical histories). However, although the material of our study was not derived from national data, a relatively big number of patients was included compared to similar studies [14,15]. Finally, it must be emphasized that although many risk factors for PPH have been identified, not all of them can be used for prevention of PPH in a clinical context [16].

\section{Conclusion}

The prophylactic administration of prostaglandins (misoprostol and, if necessary, the additional administration of prostaglandin F2a) is effective in the prevention of postpartum haemorrhage resulting in a lower decrease of postoperative haematocrit without the need for blood transfusion or invasive procedures.

\section{References}

1. WHO (2012) WHO recommendations for the prevention and treatment of postpartum haemorrhage Geneva: Dept. of Reproductive Health and Research. [pdf] WHO. Available at: https://apps.who.int/iris/bitstream/handle/10665/75411/9789241548502 eng.pdf?sequence $=1$,

2. [Accessed 18 July 2020]

3. Gallos ID, Williams HM, Price MJ, Merriel A, Gee H, et al. (2018) Uterotonic agents for preventing postpartum haemorrhage: a network meta-analysis. Cochrane Database Syst Rev 4: CD011689. [Crossref]

4. American College of Obstetricians and Gynecologists (ACOG), 2006. Postpartum hemorrhage. [pdf] Washington (DC): American College of Obstetricians and Gynecologists (ACOG). Available at: 
5. https://clinicalinnovations.com/wpcontent/uploads/2017/10/ACOG_Practice_ Bulletin_No_183_Postpartum-Hemorrhage-2017.pdf

6. Pritchard JA, Baldwin RM, Dickey JC, Wiggins KM, Reed GP, et al. (1962) Blood volume changes in pregnancy and the puerperium. Red blood cell loss and changes in apparent blood volume during and following vaginal delivery, cesarean section, and cesarean section plus total hysterectomy. Am J Obstet Gynecol 84: 1271-1282.

7. DeCherney AH, Nathan L, Laufer N, Roman AS (2019) CURRENT Diagnosis \& Treatment: Obstetrics \& Gynecology. Edition 12th. USA: Mc Graw Hill Education LANGE.

8. World Health Organization (WHO), 2019. Maternal mortality. Available at:

9. https://www.who.int/en/news-room/fact-sheets/detail/maternal-mortality, [Accessed 18 July 2020]

10. Knight M, Kenyon S, Brocklehurst P, Neilson J, Shakespeare J, et al. (2014) Saving lives, Improving Mothers Care. Learned to Inform Future Maternity Care from the UK and Ireland into Maternal Deaths and Morbidity 2009-12. [pdf] Oxford: National Perinatal Epidemiology, University of Oxford. Available at:https://www.npeu.ox.ac. uk/downloads/files/mbrraceuk/reports/MBRRACEUK\%20Maternal\%20Report\%20 2017\%20-\%20Web.pdf

11. Kominiarek MA, Kilpatrick SJ (2007) Postpartum hemorrhage: a recurring pregnancy complication. Semin Perinatol 31: 159-166.
12. Moore J, Chandraharan E (2010) Management of massive postpartum haemorrhage and coagulopathy. Obstet Gynecol Reproduct Med 20: 174-180.

13. Gülmezoglu AM, Forna F, Villar J, Hofmeyr GJ (2004) Prostaglandins for prevention of postpartum haemorrhage. Cochrane Database Syst Rev CD000494. [Crossref]

14. El-Refaey H, Nooh R, O'Brien P, M Geary, J Walder, et al. (2000) The misoprostol third stage of labour study: a randomised controlled comparison between orally administered misoprostol and standard management. BJOG 107: 1104-1110. [Crossref]

15. Bamigboye AA, Hofmeyr GJ, Merrell DA (1998) Rectal misoprostol in the prevention of postpartum hemorrhage: a placebo-controlled trial. Am J Obstet Gynecol 179: 10431046.

16. Butwick AJ, Abreo A, Bateman BT, Lee HC, El-Sayed YY, et al. (2018) The effect of maternal body mass index on postpartum hemorrhage. Anesthesiology 128: 774-783. [Crossref]

17. Gillissen A, Henriquez DDCA, van den Akker T, Caram-Deelder C, Wind M, et al. (2017) The effect of tranexamic acid on blood loss and maternal outcome in the treatment of persistent postpartum hemorrhage: A nationwide retrospective cohort study. PLoS One 12: e0187555. [Crossref]

18. Seligman K, Ramachandran B, Hegde P, Riley E, El-Sayed Y, et al. (2017) Obstetric interventions and maternal morbidity among women who experience severe postpartum hemorrhage during cesarean delivery. Int J Obstet Anesth 31: 27-36. [Crossref]

19. Iatrakis G (2020) High risk pregnancy. Athens: Desmos Digital Editions.

Copyright: $(2020$ Kourakos S. This is an open-access article distributed under the terms of the Creative Commons Attribution License, which permits unrestricted use, distribution, and reproduction in any medium, provided the original author and source are credited. 